\title{
The Prediction Of Tourist Visiting With Average Based Fuzzy Time Series Method
}

\author{
Joan Angelina Widians, Novianti Puspitasari, Andi Famela Anggita Sari
}

\begin{abstract}
This research aims to build a system which able to predict tourist visiting in the Province of East Kalimantan with Average Based Fuzzy Time Series method. Data collection in this research conducted by direct observation and interview with the Secretary on Duty of the East Kalimantan Province Tourism Department. This research uses the total numbers of tourist that visited the Province of East Kalimantan from 2008 through the year 2016 to predict tourist visit has the following years. In this research, value of MAPE is used to count the value of error or the imprecision of prediction result, so that the result of prediction will reach close to. The result of the building system is the prediction result for international tourist visiting with the MAPE value of $0,77375 \%$, which is included in the criteria of 'very good', therefore it can be concluded that this system can be used to predict tourist visiting the Province of East Kalimantan.
\end{abstract}

Keywords: Average Based; Fuzzy Time Series; MAPE value; Prediction; Tourist

\section{INTRODUCTION}

East Kalimantan Province is one of tourist destination that has interesting potential tourism which compared to Indonesia. The number of tourists who visiting the province of East Kalimantan has increased every year. The increasing of the number of tourist visiting, the government and the business community in tourism need to prepare various facilities and public infrastructure for tourists. It is done for the convenience of the tourists in order they will interested to come back visit to East Kalimantan Province. The prediction of the number of tourist who visit East Kalimantan Province needs to be accomplished, so the provincial government can anticipate the burst of tourist numbers. Therefore, it requires a system that is able to help Department of Tourism to predict tourist visiting for the future time. The Average Based Fuzzy Time Series method has been widely used as a tool to provide predictions in various purposes. For example the use of method is forecasting inbound tourism demand to Istanbul [1], to the tourism demand forecasting in China [2], forecasting tourist arrivals [3] and many more [4], [5]. The method in this study is Based Fuzzy Time Series which is a simple calculation method that has a simple structure. [6]-[8].

Revised Manuscript Received on April 19, 2019.

Joan Angelina Widians, Department of Informatics Engineering, Faculty of Computer Science and Information Technology, Mulawarman University, Indonesia(E-mail: angel.unmul@gmail.com)

Novianti Puspitasari, Department of Informatics Engineering, Faculty of Computer Science and Information Technology, Mulawarman University, Indonesia

Andi Famela Anggita Sari Department of Informatics Engineering, Faculty of Computer Science and Information Technology, Mulawarman University, Indonesia

\section{EXPERIMENTAL DETAILS}

In this study, the Fuzzy Time Series method is a data forecasting method using fuzzy principles as the basis for which the length of the interval is determined by the average based method [9]-[11]. The algorithm in the Average Based Fuzzy Time Series method used is as follows: (a) Input followings the historical data that will be predicted. (b) Determine the maximum data value $\left(\mathrm{D}_{\max }\right)$ and minimum value data value $\left(D_{\min }\right)$ from historical data. Then, find the values D1 and D2 where D1 and D2 are two appropriate and appropriate positive numbers. (c) Define Universe of Discourse (U) or set of universe with rule $\mathrm{U}=\left[D_{\min }-D 1\right.$, $\left.D_{\max }+D 2\right]$. Furthermore, determine the length interval (I) of the Universe of Discourse (U) using the Average Based method. The next step is calculate the number of intervals formed (m) using the formula (1).

$$
m=\frac{\left(D_{\max }+D_{1}-D_{\min }+D_{2}\right)}{I}
$$

As pointed in (1), $\mathrm{m}=$ the number of intervals, $\mathrm{L}=$ length of interval. (d) Divide the Universe of Discourse (U) into (U1, U2, U3, ..., Um) with the same interval length (I) as much as the interval formed (m). (e) Determine the fuzzy membership set $\left(\mathrm{A} 1, \mathrm{~A} 2, \ldots \mathrm{A}_{\mathrm{m}}\right.$ ) of the entire Universe of Discourse (U) defined by the number of intervals (m) defined in formula (2).

$$
\begin{aligned}
& A_{1}=\frac{1}{u_{1}}+\frac{0.5}{u_{2}}+\frac{0}{u_{3}}+\frac{0}{u_{4}}+\cdots+\frac{0}{u_{m}} A_{2}=\frac{0.5}{u_{1}}+\frac{1}{u_{2}}+\frac{0.5}{u_{3}}+ \\
& \frac{0}{u_{4}}+\cdots+\frac{0}{u_{m}} \quad A_{3}=\frac{0}{u_{1}}+\frac{0.5}{u_{2}}+\frac{1}{u_{3}}+\frac{0.5}{u_{4}}+\cdots+\frac{0}{u_{m}} \\
& \ldots . \quad A_{m}=\frac{0}{u_{1}}+\frac{0}{u_{2}}+\cdots+\frac{0}{u_{m-2}}+\frac{0.5}{u_{m-1}}+\frac{1}{u_{m}}
\end{aligned}
$$

The next step is perform fuzzification historical data, by giving the fuzzy membership set for historical data. For example, if the actual data lies on the Ut range, then the data belongs to the fuzzy At membership set, then Fuzzy Logical Relationship (FLR) is determined based on existing historical data. Determine Fuzzy Logical Relationship (FLR) for all historical data, where Fuzzy Ak means if the value of Fuzzy Set in year is Logical Relationship $A_{j}, A_{j}$ then in year $i+1$ is $A_{k}$. $A_{j}$ as the left side of the relationship is called the current state and $A_{k}$ as the right side of the relationship is called the next state. If there is a recurrence of the relationship then still counted once. Then, Build Fuzzy Logical Relationship Groups (FLRG). Namely by dividing Fuzzy Logical Relationship (FLR) that has been obtained into several sections or groups based on the same left side as follows: $A_{j} \rightarrow A_{k 1}, A_{j} \rightarrow A_{k 2}$ Then it will be $\rightarrow$ $A_{k 1}, A_{k 2}$.The last, calculate the predicted output. At this 
stage will be tested validation of the calculation results to ensure the results of the system has been in accordance with the needs of the Department of Tourism using Mean Absolute Percentage Error (MAPE) method. MAPE measures absolute error as average absolute error in the number of actual data periods. This can avoid problems in the interpretation of measurements of accuracy relative to the magnitude of the actual value and predictive value. The calculation of Mean Absolute Percentage Error can be seen in the following formula: MAPE $=\frac{1}{n}\left(\sum\right.$ Absolute Percent Error $)$ Where: $\quad \mathrm{N}=$ amount of actual data. The resulting value through this evaluation indicates the ability of forecasting. Where, Absolute Percentage Error value below $20 \%$ is good, and if the value less than $10 \%$ is declared very good.

\section{RESULT AND DISCUSSION}

The method of testing of Average Based Fuzzy Time Series that tested on the data of tourists visiting the province of East Kalimantan. This study uses the data of foreign tourists visiting from 2008 to 2016 as test data. The fuzzyfication results denoted into linguistic numbers can be seen in Table 1. Furthermore, in process of forecasting with fuzzy time series models, fuzzy logical relationship (FLR) is one of the most critical factors that influence the forecasting accuracy [6]. Fuzzy logical relationship (FLR) is the stage after data fuzzification, FLR in this research is $A_{1} \rightarrow A_{4}$, $\mathrm{A}_{4} \rightarrow \mathrm{A}_{5}, \mathrm{~A}_{5} \rightarrow \mathrm{A}_{10}, \mathrm{~A}_{10} \rightarrow \mathrm{A}_{9}, \mathrm{~A}_{9} \rightarrow \mathrm{A}_{13}, \mathrm{~A}_{13} \rightarrow \mathrm{A}_{34}, \mathrm{~A}_{34} \rightarrow \mathrm{A}_{30}$, $\mathrm{A}_{30} \rightarrow \mathrm{A}_{51}$. Then Fuzzy Logical Relationship (FLR) which has been formed, can be arranged into several groups based on the same left side (current state). The formed Fuzzy Logical Relationship Groups (FLRG) can be seen in Figure 1 .

Table 1: Fuzzyfication of data on the number of visits of foreign tourists

\begin{tabular}{l|l|l}
\hline Year & $\begin{array}{l}\text { Actual } \\
\text { Total }\end{array}$ & $\begin{array}{l}\text { Fuzzy } \\
\text { Set }\end{array}$ \\
\hline 2008 & 20.142 & A1 \\
2009 & 23.768 & A4 \\
2010 & 24.410 & A5 \\
2011 & 29.768 & A10 \\
2012 & 28.273 & A9 \\
2013 & 32.973 & A13 \\
2014 & 53.257 & A34 \\
2015 & 49.285 & A30 \\
2016 & 70.997 & A51 \\
\hline
\end{tabular}

\begin{tabular}{|l|l|}
\hline Group 1 & A1 $=$ A1 $\rightarrow$ A4 \\
\hline Group 2 & A4 = A4 $\rightarrow$ A5 \\
\hline Group 3 & A5 = A5 $\rightarrow$ A10 \\
\hline Group 4 & A9 = A9 $\rightarrow$ A13 \\
\hline Group 5 & A10 = A10 $\rightarrow$ A9 \\
\hline Group 6 & A13 = A13 \\
& A34 \\
\hline Group 7 & $\begin{array}{l}\text { A30 = A30 } \rightarrow \\
\text { A51 }\end{array}$ \\
\hline Group 8 & $\begin{array}{l}\text { A34 = A34 } \rightarrow \\
\text { A30 }\end{array}$ \\
\hline Group 9 & A51 = Ø \\
\hline
\end{tabular}

Fig. 1: Fuzzy logical relationship groups (FLRG Aboard)

The next step is calculate the prediction result. In 2017, due to the fuzzyfication result of the number of foreign tourist arrivals in 2016 in Table 1 is A51, and from Figure 1 it can be seen that A51 does not have Fuzzy Logical Relationship Group (FLRG) with current state that formed A51:A51 the maximum membership value for the A51 fuzzy set occurs at the interval U51, with U51 $=[70,000$, $71.000]$, and the middle value of the U51 interval is 70,500. As a result the prediction of the number of foreign tourists who visit the province of East Kalimantan in 2017 is 70,500 can be seen in Table 2. The prediction result for foreign tourist visiting on prediction system can be seen on Figure 2 . Then, calculate Absolute Percent Error (APE) from foreign data for each year that has actual number and predicted results from 2009 to 2016. In 2008 it cannot be calculated, as it has no predicted results. After obtaining the Absolute Percent Error result from the foreign data, then the MAPE value obtained for foreign data with the amount of data $\mathrm{n}=$ 8 is $0.77375 \%$. This indicates that prediction results for foreign data are included in very good criteria based on Table 2 because the MAPE value is obtained below $10 \%$.

Table 2: Prediction result

\begin{tabular}{c|c|c}
\hline Year & Actual Total & Prediction Result \\
\hline 2008 & 20.142 & - \\
2009 & 23.768 & 23.500 \\
2010 & 24.410 & 24.500 \\
2011 & 29.768 & 29.500 \\
2012 & 28.273 & 28.500 \\
2013 & 32.973 & 32.500 \\
2014 & 53.257 & 53.500 \\
2015 & 49.285 & 49.500 \\
2016 & 70.997 & 70.500 \\
2017 & - & 70.500 \\
\hline
\end{tabular}




\section{Prediction Result of International Tourist Visit}

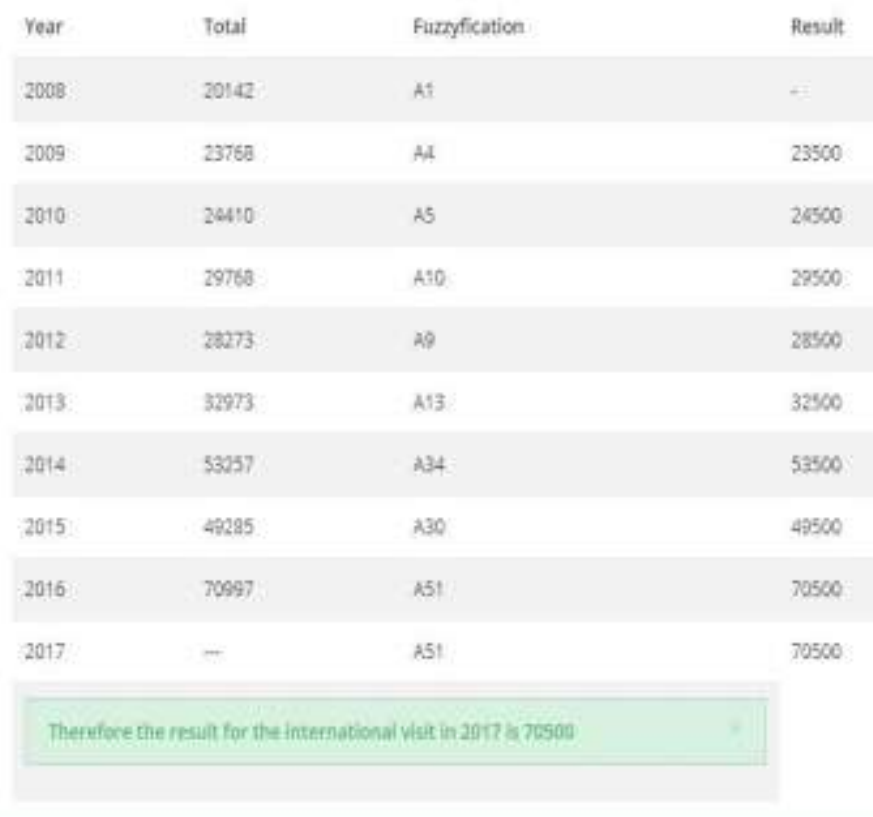

\section{CONCLUSION}

The conclusion obtained from this research are: 1) This system is able to give very good prediction result in the prediction process of tourist visit to East Kalimantan Province using method of Average Based Fuzzy Time Series so that predictions obtained more precise, computerized and prevent decision making which is subjective. 2) Using the Average Based Fuzzy Time Series method, the MAPE value is $0.77375 \%$ for foreign data and $4.26 \%$ for the archipelago data, both of which are included in the criteria very well. Because the MAPE result is less than $10 \%$.

\section{REFERENCES}

1 M. Çuhadar, "Modelling and forecasting inbound tourism demand to Istanbul-A comparative analysis," Eur. J. Bus. Soc. Sci., vol. 2, no. 12, pp. 101-119, 2014.

2 Y. Li, H. Cao, and H.-Y. Meng, "A Hybrid Tourism Demand Forecasting Model Based on Fuzzy Times Series," in 2016 International Conference on Artificial Intelligence and Computer Science, 2016, pp. 171-177.

3 S. M. A. Mutalib, N. Ramli, F. N. Zainoordin, and Z. A. G. Hilmi, "Forecasting Tourist Arrivals Based on Fuzzy Approach with Average Length and New Base Mapping," in Business Management and Computing Research Colloquium (BMCRC), 2016.

4 S. H. Cheng, S. M. Chen, and W. S. Jian, "Fuzzy time series forecasting based on fuzzy logical relationships and similarity measures," Inf. Sci. (Ny)., vol. 372, pp. 272-287, 2016.

5 K. Bisht and S. Kumar, "Fuzzy time series forecasting method based on hesitant fuzzy sets," Expert Syst. Appl., vol. 64, pp. 557-568, 2016.

6 W. Qiu, P. Zhang, and Y. Wang, "Fuzzy Time Series Forecasting Model Based on Automatic Clustering Techniques and Generalized Fuzzy Logical Relationship," Math. Probl. Eng., vol. 2015, no. 962597 , 2015.
7 R. Sivasamy and N. O. Ama, "Mixed average-based fuzzy time series models for forecasting futurecivilian fatalities by terrorist attacks in south Asia," Int. J. Phys. Math. Sci., vol. 4, no. 1, pp. 20-25, 2014.

8 Mislan, A. F. O. Gaffar, Haviluddin, and N. Puspitasari, "Water Level Prediction of Lake Cascade Mahakam Using Adaptive Neural Network Backpropagation (ANNBP)," in 1st International Conference on Tropical Studies and Its Application (ICTROPS), 2018.

9 P. Singh, "An efficient method for forecasting using fuzzy time series," in Emerging Research on Applied Fuzzy Sets and Intuitionistic Fuzzy Matrices, 2017, pp. 287-304.

10 K. G. Tay, Y. Y. Choy, and C. C. Chew, "Forecasting Electricity Consumption Using Fuzzy Time Series," Int. J. Eng. Technol., vol. 7, no. 4.30, pp. 342-346, 2018.

11 S. Keliwar, A. Bramanto Wicaksono Putra, J. Hammad, and Haviluddin, "Modeling of time series data for forecasting the number of foreign tourists in east Kalimantan using fuzzy inference system based on ARX model," Int. J. Eng. Technol., 2018. 